\title{
Serving Public Interests in Educational Accountability: Alternative Approaches to Democratic Evaluation ${ }^{\text {is }}$
}

\author{
KATHERINE E. RYAN
}

Available online 29 September 2004

\begin{abstract}
Today, educational evaluation theory and practice face a critical juncture with the kind of educational accountability evaluation legislated by No Child Left Behind. While the goal of this kind of educational accountability is to improve education, it is characterized by a hierarchical, top-down approach to improving educational achievement reflecting a climate of control and efficiency. Democratic evaluation is intended for contexts in which there are concerns about top-down control of management and education (MacDonald, B. \& Kushner, S. (2004). Democratic evaluation. In S. Mathison (Ed.), The encyclopedia of evaluation. Thousand Oaks, CA: Sage). This paper examines democratic evaluation approaches to see how these approaches might contribute to making educational accountability more democratic. Suggestions about how evaluators can serve public interests in developing a more democratic accountability are presented.
\end{abstract}

\section{SERVING PUBLIC INTERESTS IN EDUCATIONAL ACCOUNTABILITY}

Audit cultures continue to intensify nationally and globally (Power, 1997)—reflections of New Public Management. ${ }^{1}$ The U.S. educational accountability context reflects this audit intensification, particularly since the passage of the No Child Left Behind Act of 2001 (NCLB). This legislation essentially institutionalizes the reliance on performance indicators as a key mechanism for improving student achievement. On the one hand, the audit culture's performance indicators serve stakeholders and public interests through monitoring. At the same time,

Katherine E. Ryan • Department of Educational Psychology, 230 Education, 1310 South Sixth Street, Champaign, IL 61820, USA; Tel: (1) 217-333-0719; Fax: (1) 217-244-7620.; Email: k-ryan6@uiuc.edu (K.E. RYAN)

An earlier version of this paper was presented at the 2003 American Evaluation Association Meeting, 4 November.

American Journal of Evaluation, Vol. 25, No. 4, 2004, pp. 443-460. All rights of reproduction in any form reserved. ISSN: 1098-2140 C 2004 American Evaluation Association. Published by Elsevier Inc. All rights reserved. 
however, educational accountability is characterized by a hierarchical top-down approach to improving educational achievement reflecting a climate of control and efficiency-a 'new rationality of governance' (Power, 1997, p. 10). The reductive nature of these indicators tends to shape program quality representations that are oversimplified (Stake, 2001). While the goal of educational accountability systems is well-intended - to improve education-the information from these systems is not sufficiently informative. They do not provide information about what to do and how to improve education and student learning (Ryan, 2002). Furthermore, the climate of control restricts local school autonomy and teacher professionalism (House, 2005). Whether the educational interests of stakeholders, the public, and society are served by this kind of centralized authority is not clear.

Historically, democratic evaluation was especially sensitive to local educational issues (MacDonald, 1976; Simons, 1987). Democratic evaluation has been highly influential in the theory and practice of evaluation since the early 70s. This approach is distinguished by its evaluation purposes, values, methodology (case study), and intended uses, for example. Democratic evaluation has a long standing history, at least in Great Britain, to champion the "public right to know." The intellectual vitality of this tradition is reflected in the continuing advances in both evaluation theory and practice. For instance, new terrain in democratic evaluation (e.g., deliberative democratic evaluation, House \& Howe, 1999; communicative evaluation, Niemi \& Kemmis, 1999; and others, including Ryan \& DeStefano, 2001), have been charted in this tradition in the last 5 years.

Thirty years ago, democratic evaluation provided answers to foundational dilemmas in educational evaluation by articulating a new vision for evaluation. These dilemmas included issues such as addressing power relations in the evaluation context, how to include stakeholders' perspectives, and providing useful information to programs (e.g., Guba, 1969; MacDonald, 1976). Today, educational evaluation theory and practice face another critical juncture with the kind of educational accountability evaluation legislated by No Child Left Behind.

There is particular interest in what role democratic evaluation can play in the current British and U.S. accountability climate (McKee \& Stake, 2002; Ryan, 2002). For example, issues such as who should make policy, how to find out and represent various stakeholder groups' values, and the relative position of stakeholders are, in some senses, old evaluation dilemmas. However, within the hierarchy of NCLB educational performance monitoring, which does not include stakeholders' perspectives, these issues represent evaluation dilemmas with a new face. How the moral and intellectual commitments of democratic evaluation approaches can be fitted to the current educational accountability landscape remains unresolved.

In this paper I critically examine three democratic evaluation approaches: democratic evaluation (MacDonald, 1976), deliberative democratic evaluation (House \& Howe, 1999), and communicative evaluation (Niemi \& Kemmis, 1999). My review is necessarily selective; and in some cases, adherents of these approaches may not agree with all the characterizations I present. All three approaches are significant within the evaluation field and in some cases are still in the early stages of development (e.g., communicative evaluation). While these approaches are related, there are vital distinctions. Comparing and contrasting these approaches, then, will offer a deeper understanding of their respective theories and practices, in addition to identifying possible implications for serving public interests in a performance indicator world.

My examination includes a brief discussion of their respective theoretical foundations and evaluation practices. As part of the examination, I present a case vignette for each, illustrating the respective democratic evaluation approaches. These vignettes are drawn from Simons, Kushner, James, and Jones (2001; democratic evaluation), Howe and Ashcraft (in 
press: deliberative democratic evaluation) and Brooks, Ryan, and Miron (2003; communicative evaluation). My analysis of each case reveals the theoretical and practice distinctions and similarities of each approach. These approaches are then examined within a descriptive framework including democratic foundations, institutional location, evaluation methods, knowledge generation, evaluator role, and communicative practices. I close with a brief discussion of how democratic evaluation can contribute to serving the public interest in education in this climate of control.

\title{
DEMOCRATIC EVALUATION GENRES
}

\section{Democratic Evaluation}

\begin{abstract}
"The position of the evaluator is quite distinct ..."[he] soon discovers ... that his script of educational issues, actions, and consequences is being acted out in a socio-political street theatre which affects not just the performance but the play itself." (MacDonald, 1976, p. 130)
\end{abstract}

No discussion of democratically-oriented evaluation approaches can take place without a consideration of MacDonald's (1976) democratic evaluation. In his seminal paper on evaluation's political dimension, MacDonald defined three forms of evaluation: autocratic, bureaucratic, and democratic. In bureaucratic evaluation, the evaluator is located within the "ruling apparatus 2 " or institutional power structures-essentially preserving the current often hierarchical power relationships. Within autocratic evaluation, the evaluator is positioned as an "outside expert." The evaluator's social science knowledge is valued as science. In turn, this knowledge is used to warrant the ruling apparatus or institutional power structures including public policy.

In contrast to these other forms, the democratic evaluator serves as independent knowledge broker effectively setting the stage for shifts in the distribution of power relationships in the evaluation context. The redistribution of power is accomplished by (a) "democratizing knowledge" and (b) holding all groups in the evaluation context, including the client, mutually accountable. That is, the program knowledge discourses are as valued (or more so) than the social science or technocratic knowledge discourses. Consequently, in this evaluation context, all groups have claims to a "unique domain of knowledge" (Noddings, 1984). While perhaps not a long-term change, this procedure rearranges power relations in that program knowledge is more equally distributed than are power relations (Simons, 1987). Mutual accountability is justified as part of a Lockean liberal democracy (Locke, 1988). Here government is constituted as delegated, institutional power structures administering the interests of society ${ }^{3}$-and held to a collective accounting.

The public right to know is framed from this notion of democracy. That is, power is vested in the people and, like the institutional structures administering the interests of public, the evaluator should also serve the public (ordinary citizens interested in or affected by concerns and representing multiple viewpoints). The evaluator's public service obligation includes those distant and near to power (McKee \& Stake, 2002). Thus, in a climate characterized by "who gets to know what and whose interests are being served", serving the public right to know began as a strategy to address this political economy of information.

A particular kind of case study method is linked to democratic evaluation (Simons, 1987). Here the program is seen as a case — not as a structure with different parts that can be studied (Stake, 1995). In contrast to the theory-based case study associated with the educational 
research tradition, the "democratic" case study is practice-based (MacDonald \& Walker, 1975; Simons, 1987). Here the evaluator represents the groups involved, which includes using practitioners' definitions, language, and theories of about the program (Simons, 1987). Further, the democratic, practice-based case study includes techniques practitioners could use themselves to understand themselves and others (including policy makers)—a form of critical reflection. A "collaborative case study ethic" has been justified by the evaluation economy of scale characterized by limited resources (Simons, 1987). More importantly, with a democratic case study approach, a “... self monitoring education community” (MacDonald \& Walker, 1975, p. 11) is essentially established when framing the program as a case where the actors are implementing policy and engaging in critical reflection about implementation.

Moving to the larger socio-political context, when accessible to powerful groups, the case is the means by which change in policy initiatives becomes possible, by revealing the gaps between what is actually happening in a particular context compared to the ideal that is intended (MacDonald, 1999). As a profession or institution devoted to disclosing these gaps, evaluation is positioned as a service to a society committed to self-improvement (Simons, 1987). Hence, evaluation serves the public interest by improvement of public institutions. Within this logic, change is leveraged by holding all players, including the policymakers, mutually accountable for the disparities between what was actually happening in the programs and the original policy intent.

Interestingly, there are substantial tensions for the role of the democratic evaluator in theory and practice. In spite of these complexities, democratic evaluation has been implemented successfully in Great Britain for nearly 30 years (e.g., MacDonald \& Kushner, 1982; MacDonald \& Walker, 1976; McKee \& Stake, 2002). Being respectful of authority is a foundational principle; at the same time, the evaluator is expected to be independent from power relationships while reliant on these authorities for at least financial resources. While democratic evaluation theory directly acknowledges value pluralism, in practice, the democratic evaluators do not promote their values and ideology or make decisions about which values are legitimate. These decisions are left to the actors in the evaluation including the public.

To enable deliberations about these decisions, the evaluation report is constructed in accessible language and aimed at the widest possible distribution- "aspires to best seller status" (MacDonald, 1976, p. 134). This widespread distribution is intended to provide an opportunity for the public to engage in debate or deliberation about issues of interest and concern. In contrast to traditional evaluation reports containing recommendations of what to do next, the democratic evaluation report sets the stage for a debate or discussion about what should happen next (Simons, 1987).

In the next section, I present a case vignette from an attempted democratic evaluation of a national program designed to develop evidence-based practice for teachers (Kushner, Simons, Jones, \& James, 2003). I briefly describe the evaluation, highlighting the descriptive characteristics of democratic evaluation, such as the means by which democratic evaluators set the stage for a shift in power relations by democratizing knowledge. Many democratic evaluations have been implemented successfully (e.g., McKee \& Stake, 2002); at the same time, this vignette illustrates the difficulties of implementing democratic arrangements in evaluation, particularly in the face of a skillful bureaucratic apparatus. A brief case analysis follows, emphasizing the theoretical features of democratic evaluation such as the role of the democratic evaluator. 


\section{Serving the Public Right to Know ${ }^{4}$}

Vignette 1. The Schools-Based Research Consortium Initiative, devoted to developing evidence-based practice among teachers, was evaluated in the British democratic evaluation tradition from 1999 to 2001 (Simons, Kushner, James, \& Jones, 2003). The original program intentions were to drive pedagogical development with research evidence-generated by teachers themselves or discovered and adapted by them. However, the program evolved to an evidence informed practice explicitly acknowledging the centrality of teachers' professional judgment about evolving pedagogies.

From the start, the evaluators faced challenges that shaped the course of the evaluation. These included a late start (program operations began one year prior to the evaluation initiation), and a complex relationship with the program manager and evaluation sponsor who was contracted as an independent to provide these service by the Teacher Training Agency (TTA). This agency, which actually commissioned the program and program evaluation, is accountable to the Minister for implementing government teacher policy, but lies outside of government ministries and is not directly accessible to parliamentary scrutiny. With such distance from the government and the program, these were not ideal conditions for a democratic evaluation, where establishing a position with access to power and with the program participants is an important means for leveraging information exchange on a fair and equal basis. At the same time, there was clearly a democratic intent to the program. It was aimed at valuing the teachers' perspectives and judgment about scientific evidence and their professional practice.

The evaluators did seek to adopt a democratic evaluation approach by treating all stakeholders the same with respect to information, perspectives, and evaluation demands. The evaluation's ethics protocol — negotiated with program participants—limited the evaluators' publication rights, ensuring that evaluation report drafts would be negotiated at workshops and forums as well as with individuals, where possible. These negotiations of draft reports were to include the TTA as sponsor, but on the same terms as the program participants. In spite of evaluators' efforts to neutralize status, the TTA program managers, as they had informed the evaluators during the contractual negotiations, insisted on monitoring the evaluators' work closely. They invited the evaluators to expand their project to include the work of the TTA—which lent itself to a democratic evaluation - but they also sought to influence the evaluation design (sampling, data sources), and even suspended evaluation field work at one point. All of these they did in order to protect teachers and schools from the possibility of harm or interruption by the evaluation. Responding to these demands, however, seemed to give the sponsor more access to the evaluation than other groups. A further complication which compromised the independence of the evaluation was that the TTA also sponsored teacher education programs in the evaluators' own universities, and at one point one of these universities - caught in the dilemma of protecting an income stream while supporting independent research-sought to influence the evaluators in a dispute over contractual obligations.

Case analysis. This case illustrates the kinds of tensions rooted in the democratic evaluator role in practice. According to democratic evaluation theory, the evaluator is a neutral broker within networks of power and authority. Nevertheless, these democratic evaluators were reliant on the TTA for the financial resources to conduct the evaluation. The TTA took the position that their evaluation financing gave them the right to manage the evaluation and they asserted their interpretations of contractual obligations by suspending field work. The evaluators, on the other hand, advanced the conventional argument that they could (democratically) be "sponsored" 
but not "bought." That is, the TTA could pay for the evaluation, but only as a resource for all stakeholders, none of which, including themselves, would have special access.

This case also reveals the critical importance of positioning an independent democratic evaluation vis a vis the program relationships. The evaluators were not able to build a base of trust and cooperation among program participants because of their late start. They did not, either, have direct access to the Ministerial authority who oversees the TTA. While the presence of these relationships would not have guaranteed success, the democratic evaluators did not have these relationships as assets. The lack of these relationships as resources was even more problematic because the TTA demands were so large. As a consequence, the capacity for the evaluators to respond to other voices or information needs in the evaluation was limited. The democratic evaluator role of independent information broker within and across the program could not be fully enacted (it was to a limited extent - they did circulate drafts and reports). Further, the evaluators were unable to hold all groups including the TTA to a collective accounting (mutual accountability). Crucially, while there may have been times when evaluation reporting was subject to restrictions, the public right to know was preserved through the discussions of draft reports as allowed for in the agreed-upon ethics protocol - that is, negotiation procedures meant that significant elements of evaluation reports were in the public domain prior to final report negotiations. Overall, the threat to the independence and to the public credibility of the evaluation were the greatest stumbling blocks to their democratic intent.

\section{DELIBERATIVE DEMOCRATIC EVALUATION}

"In this conception, the evaluator is not a passive bystander, an innocent facilitator, nor a philosopher king ... rather a conscientious professional who adheres to a set of defensible, carefully considered set of principles for enhancing inclusion, dialogue, and deliberation." (House \& Howe, 1999, p. 6)

Deliberative democratic evaluation is conceptualized around the notion that evaluation theory and practice should reflect the society in which it is embedded-a society that advances democracy (House \& Howe, 1999). Acknowledging the reciprocal relationship between evaluation and society, House and Howe (1999) further suggest that "evaluation . . . can be vital to the realization of a democratic society" (p. 2). This link is made explicit when evaluations are based on principles of deliberative democracy.

To accomplish this, House and Howe present an overall framework for judging evaluations on the basis of their potential for democratic deliberation. Democratic deliberative evaluation is characterized by three principles: deliberation, inclusion, and dialogue. Deliberation is defined as reasoning reflectively about relevant issues, including the identification of preferences and values. Inclusion is defined as including all relevant interests, stakeholders, and other citizens with specific concerns. The approach is also dialogical. Stakeholders and evaluators engage in dialogues in the evaluation process. Through dialogue, stakeholder interests, opinions, and ideas can be portrayed more completely.

By meeting these three foundational conditions, deliberative democratic evaluation aims at equalizing power relationships in making evaluative judgments. Further, how evaluation serves the public interests is clearly articulated within deliberative democratic evaluation. Evaluation serves the public interests by informing public opinion with a particular kind of warranted conclusion characterized as "objective." Here objectivity is operationlized as "including views and interests, promoting dialogue, and fostering deliberation toward reaching valid conclusions ... and by the professional expertise the evaluator brings ..." (p. 97). 
Within deliberative democratic evaluation, evaluators have a special obligation to participants and the public at large because evaluators are "constrained by the value of promoting democracy" (House \& Howe, 1999, p. 137). Further, within this conceptualization of the evaluator's role, evaluators should promote a democratic sense of justice, be skilled negotiators, and be prepared to take positions on vital political and moral issues. In efforts to identify stakeholders' genuine interests, the evaluator is willing to negotiate some impartiality to gain more understanding of stakeholders' perspectives (House \& Howe, 1999).

The ideology of deliberative democratic evaluation is clear. This approach is aimed at addressing complex issues in evaluation through a commitment to some form of democratic principles. Democratic deliberative evaluation is analytically distinct from approaches such as responsive evaluation (Stake, 1984), democratic evaluation (MacDonald, 1976; Simons, 1987), and fourth generation evaluation (Guba \& Lincoln, 1989). This is so because within this framework, evaluation is linked to the larger social-political, moral structures and these connections are intended to be democratic. While there are many theories of democracy, House and Howe propose that deliberative democratic evaluation reflects the principles of participatory democracy proposed by Gutmann (1987). Briefly, in addition to the notion that all parties should be included in reaching governing decisions, Gutmann also proposes that promoting joint deliberation by citizens on matters of social policy or "conscious social reproduction" is a central tenet of democracy.

The methodology outlined in deliberative democratic evaluation for reaching valid conclusions is about how to 'reason' in evaluation-what do we do and what is reasoning in evaluation. The form of reasoning proposed within the framework can be linked to the principle of reciprocity, a foundational notion in deliberative democratic theory (Gutmann \& Thompson, 1999). Reciprocity is the capacity and will to seek fair terms of cooperation for its own sake. That is, public reasoning is regulated by saying people have to reason beyond their own narrow interest and think about what can be justified to people who disagree with them. Reciprocity is characterized by a moral and an empirical dimension. The moral dimension incorporates a mutually recognizable moral principle like basic opportunity for all citizens (equal educational opportunities). The empirical dimension involves using "relatively" reliable methods of inquiry and ignores implausible assertions that are not logically consistent.

Like democratic evaluation (MacDonald, 1976), deliberative democratic evaluation advances evaluation theory by articulating democratic processes such as inclusion, dialogue, and deliberation in the evaluation context and by linking these processes to the larger democratic institutional structures. Claims to improving practice are more equivocal. While the notion that deliberative democratic evaluation may be too idealized to be put directly into practice is explicitly acknowledged (House \& Howe, 1999), case illustrations of deliberative democratic evaluation suggest even partial implementation of this approach is helpful for enacting democratic processes (e.g., Howe \& Ashcraft, in press; Ryan \& Johnson, 2000; although see Greene, 2000, for an exception).

The following vignette provides an example of how deliberative democratic evaluation can be implemented at the local level within the educational accountability context. The summary of this evaluation illustrates, for instance, how this approach is instantiated in practice, including the use of mixed methods and how the notion of values is articulated. The vignette shows how deliberative democratic evaluation can help schools engage in self-accountability (Rizvi, 1990; Simons, 1981), a notion that is directly linked to democratic evaluation in the British tradition. ${ }^{5}$ The case analysis reveals the theoretical features that mark deliberative democratic evaluation from other approaches. 


\section{Contributing to Making Society More Democratic}

Vignette 2. This investigation reports a case study evaluation of school choice policy effects (Howe \& Ashcraft, in press) framed within the democratic evaluation perspective (House \& Howe, 1999). While school choice (open enrollment) in Boulder Valley School District, Boulder, CO was originally intended to focus on diversity, bilingual education, and the like, by the mid-90s, options began to emphasize academic achievement and college preparation (Howe \& Ashcraft, in press). While ensuring objectivity (concerns would be empirically investigated), the evaluators did make it clear that value-related issues would be part of the evaluation, including the tensions (e.g., increases in racial stratification) surrounding the school choice policy.

After identifying parents, teachers, and school administrators as stakeholders, the evaluators incorporated inclusion with representative survey samples and focus groups of these stakeholders across levels (e.g., elementary) and school type (choice vs. neighborhood) (Howe $\&$ Ashcraft, in press). The focus groups were the primary forum for dialogue within the actual evaluation. Howe and Ashcroft (in press) characterized the dialogue as "elucidating" rather than critical. In the spite of controversial findings about school choice inequities, such as skimming (students with higher test scores applied to open enrollment middle and high schools with higher test scores), increases in racial and low income stratification since the 90s, and funding inequities (choice schools had higher per pupil costs), there was little deliberation during the evaluation process. The school board and local school officials did use the findings to justify changes like a centralized enrollment system to ensure consistency in enrollment requirements. Further, in interviews, the board and school officials reported that the study findings were "a shield from criticism and attack, particularly from charter schools who hotly contested the centralization process" (Howe \& Ashcraft, in press, p. 26). Interestingly, after the evaluation was complete, findings were taken up in public discourses (e.g., the media, mild public responses, local policy makers) where these issues were deliberated.

Case analysis. This case study evaluation illustrates how deliberative democratic evaluation can contribute to helping institutions become more democratic by illuminating tensions and issues related to institutional inequities through inclusion, dialogue, and deliberation. This is the aim of deliberative democratic evaluation. While revealing the difficulties with employing this approach in its ideal form, modest forms of inclusion and dialogue were implemented with no real deliberation in the actual evaluation implementation. Vignette 2 suggests that even partial implementation, such as the passive and active forms of inclusion (survey and focus groups) and dialogue (focus groups), is helpful for enacting democratic processes. The modest implementation represented in this case vignette shows how small shifts in power relations to some extent permit issues like inequities in school fund-raising capacities to surface.

Further, the evaluation findings contributed to making institutional structures more democratic when policy makers changed to a central enrollment process. In this case, it was to the district's advantage to commission a democratic evaluation because they got ahead of a problem (rising racial stratification). The centralized enrollment process allows school officials to balance school enrollments, moderating the potential for racial stratification, which in turn contributes to making a public institution (education) more democratic. Importantly, the public discourses created a forum for citizens to engage in practical deliberation about the study findings, meeting the deliberation requirement (Howe \& Ashcraft, in press) and involving the 
community. In this case, the evaluator served in an external role assisting in a district's effort at self-accountability by examining their school choice policy.

\section{COMMUNICATIVE EVALUATION}

“... we would expect a different kind of relationship between stakeholders and evaluator

... the 'outside' evaluator would become a co-evaluator ... and perhaps a co-participant

... evaluators should expect to become insiders ..." (Kemmis, personal communication)

Communicative evaluation is framed around the notion that there are two broad perspectives in evaluation today: (a) evaluation serving the needs of decision makers (Mark, Henry, \& Julnes, 2000) and (b) evaluation aimed at creating a space for practical deliberation (House \& Howe, 1999; Niemi \& Kemmis, 1999). Articulated as a partial antidote to the uncertainty of postmodernism, the primary purpose of communicative evaluation is to create spaces for communication about critical issues and themes emerging from the social and educational program and context. Communicative evaluation is most similar to responsive evaluation (Stake, 1984), democratic deliberative evaluation (House \& Howe, 1999), participatory evaluation (Whitmore, 1998), and empowerment evaluation (Fetterman, 1994). ${ }^{6}$ However, communicative evaluation can be distinguished from these previous approaches by the communication practices within this framework.

The communicative practices for communicative evaluation are based on Habermas's model of public discourse within democracies and more recent developments involving the notions of public sphere and public discourse (Habermas, 1996). Public discourse is formed by multiple networks of continuous, sustained informed communication and ideas concerning a civic issue within the public sphere (Bacon, Yuen, \& Korza, 1999). Public discourse includes dialogues, private and public conversations, organized deliberative forums, the print media, televised reporting, internet sites, and political debates. A public sphere is a space in modern society in which political participation is enabled through conversation (Fraser, 1993; Habermas, 1989). Forming communication networks, public spheres are a diversity of associations or movements that are more or less informal or loosely configured groups based on common interests or concerns. In these conversational spaces, citizens can come together to debate and deliberate, creating discourses that may be critical of the state and that have the potential for contributing to the development of new and or different public policies or programs (Niemi \& Kemmis, 1999).

These concepts enable a communicative evaluation theory and practice that aims to identify issues for practical deliberation at the local level (the program and its context). That is, the evaluation context can be considered as a site for conversation among stakeholder groups who are conceptualized as one or more actual networks of communication (public spheres). These stakeholder groups form to foster communicative action, which involves intersubjective agreement, mutual understanding, and unforced agreement about what actions to take (Kemmis \& McTaggart, 2005). Further, the practical deliberation at the local level can contribute to the larger social context by contributing to the public discourse concerning these issues which can lead to new public policies or programs.

Communicative evaluation is characterized by three distinct functions: revelation, anticipation, and building communication and partnerships (Niemi \& Kemmis, 1999). Revelation brings to light taken-for-granted understandings about critical issues in and around the program. Anticipation aims people and groups in the program and context towards future problems and opportunities. Building communication and partnerships is intended to develop 
relationships among people and groups so they can act collaboratively and wisely to take action.

Communicative evaluation is related to participatory action research (PAR) or selfevaluation (Kemmis \& McTaggart, 2005). Three characteristics distinguish communicative evaluation from more traditional evaluation approaches: shared ownership of the evaluation, a community-based view and analysis of the educational or social problem, and an orienting toward community action. While difficult to reduce to a set of steps, there is a sequence of self-reflective cycles of activities, guided by communicative action, which form the core of communicative evaluation (Kemmis \& McTaggart, 2000):

- Planning a change

- Enacting the change and observing the change process and consequences of change

- Critically reflecting on the process and consequences

- Making judgments about the process and consequences

- Re-planning

- Acting and observing...

There is a different kind of relationship between stakeholders and the evaluator in communicative evaluation. Stakeholders become co-evaluators with the evaluator and evaluators become collaborators and co-participants with the stakeholders in improving some educational or social problem (e.g., decreasing the drop out rates in Plains). The evaluator role is no longer authoritative (or autocractic). The asymmetry that characterizes the traditional evaluator role relations within the evaluation context is shifted toward a more symmetrical relation. In contrast to the more traditional evaluator role of "information carrier," the evaluator enables and extends communication among participants and groups. Further, communicative evaluation is not intended to replace traditional evaluation where evaluation is part of institutional, hierarchical structures. These companion evaluations are best considered "different lens" offering a unique, in-depth view of issues by considering two different images of a program from distinct perspectives. $^{7}$

Communicative evaluation is a newer form of democratic evaluation; various parts of the theory are just being articulated. Reflecting its Habermasian roots, there is a substantial theoretical apparatus with this approach providing significant conceptual resources. However, whether this kind of theoretical apparatus is really helpful by solving current and historical evaluation dilemmas is not yet clear. The notion that findings from the local evaluation can contribute to addressing the same issues in the larger context is intriguing. That communicative evaluation theory articulates to some extent how this might be accomplished (through public discourse and public spheres) is also of interest. The Habermasian framework also brings significant issues. The concept of public sphere and/or public spheres has been widely criticized (e.g., Fraser, 1993). In addition, Habermas's emphasis on unforced consensus has been the subject of disapproval for failing to adequately represent diversity and power relations (Young, 1999).

The following case vignette is from a communicative evaluation of a community project designed to support African American seniors graduate from high school. The brief description of this evaluation particularly emphasizes the shift in the evaluator's role in communicative evaluation-a distinct characteristic of this approach. In this case, communicative evaluation provides information that is informative by identifying possible ways to improve student learning which is markedly different than the kinds of information provided by educational accountability systems. The case analysis illustrates the theoretical attributes of communicative 
evaluation like the use of critical mixed methods and how this evaluation is located outside formal institutional structures.

\section{Providing Effective Support for Social Change}

Vignette 3. The evaluators present preliminary findings from the first phase of a communicative evaluation examining a community project aimed at ensuring that the African American seniors in Plains, IL, stay on target for high school graduation each year (Brooks et al., 2003). Campaign 155, directed by local parent and community leaders from the Urban League, is aimed at contributing to the public discourse on how to improve educational achievement for minorities and to take concrete actions to increase local graduation rates. The concrete actions include identifying and following the seniors who begin to falter and to offer support services including a tutorial program.

Evaluators (faculty and students) and the Urban League are working in partnership to evaluate the project. The Urban League staff defined evaluation questions and prepared the interview protocol with assistance from the university team. In addition, the Urban League staff conducted the interviews and conversations with non-graduating and graduating seniors after receiving modest training in methods (interviews and focus group). The faculty-student evaluators conducted the data analysis and prepared a draft report. The seniors identified three key areas of concern that significantly affected their high school experiences: course scheduling and enrollment, social support systems, and student engagement. The faculty-student team released the report to the Urban League in draft form with a caution not to distribute to the public. Nevertheless, the results from the study were distributed as a press release by Ms. Brown, Campaign 155 leader, although the study findings were not reported in the newspaper.

Case analysis. This case illustrates how evaluators can provide support for stakeholders' actions, organizations, and communities aimed at social change - the aim of communicative evaluation. Vignette 3, which examined the achievement gap between white and African American students in Plains, IL, illustrates how communicative evaluation is located outside the institutional structures. In contrast, educational accountability evaluations examine the achievement gap by considering the achievement of state learning standards by different groups represented by test scores ( 4 is proficient, 3 is meeting standards, 2 is below standards, etc.) on the Illinois School Report Card (ISRC) (institutional efficiency indicators).

A communicative evaluation instituted by community members is committed to addressing the achievement gap by studying the kinds of tutorial support available, school climate and social support, and whether English courses are a particular obstacle for students. In fact, the areas of concerns identified (lack of social support, course scheduling) presents a very different picture than the $I S R C$, which is the intent of communicative evaluation. In contrast, the ISRC is an annual performance measurement reporting on student tests scores and other indicators (school demographics, high school graduation rates, and poverty rates). The ISRC serves as the annual evaluation that is part of the institutional hierarchical structures.

The vignette also reflects how the evaluator role changes when evaluators assume a coevaluator instead of a traditional evaluator role. For example, a change in the authority relations is reflected in the report distribution. There also may need to be a multi-pronged strategy for getting findings into the public discourse for practical deliberation - a press release may not be enough. Further, there is also a tradeoff when interviews are conducted by 'insiders' like Urban League staff. On the one hand, their technical expertise in conducting interviews is modest 
compared to the training many evaluators receive. On the other hand, as insiders, their cultural expertise is not questioned, particularly on cultural dimensions that may elude the 'outside' evaluator.

In the next section, I delineate democratic evaluation, deliberative democratic evaluation, and communicative evaluation as three alternative evaluation approaches. I examine these three approaches based on a set of descriptive categories, such as foundations, values, institutional location, key concepts, and issues formulation; these were derived from my discussion above and from distinctions identified by others (e.g., MacDonald, 1976). A discussion of the three approaches' respective theoretical foundations and evaluation practices is included.

\section{FRAMEWORK FOR EXAMINING DEMOCRATIC EVALUATION GENRES}

Table 1 presents a descriptive cataloging of these democratically-oriented evaluation approaches. Clearly, a table such as this fails to capture all of the theoretical complexities and is an oversimplification of any theory. In addition, as this table demonstrates, while there theoretical distinctions among these approaches, similarities are clearly evident. These democratic evaluation approaches are, in many respects, compatible. As the case vignettes and descriptive categories in the table show, the differences among these genres especially blur in relation to evaluation practice.

\section{Evaluation Theory}

The democratic foundations differ in important ways. There is an almost developmental character here. In contrast to the foundations of democratic evaluation (liberal democracy), the concept of participation is central in both participatory (deliberative democratic evaluation) and deliberative democracy (communicative evaluation). The role of participation shapes both the theory and practice of deliberative democratic evaluation and communicative evaluation. There are notable differences in values, such as the notion of emancipation which is reflected in communicative evaluation. Here stakeholders become aware of contradictions within their lives and take social action to change these circumstances. Vignette 3 illustrates this when stakeholders are the owners of the evaluation, actually conceptualizing and conducting much of the communicative evaluation themselves. Nevertheless, when considering the kinds of values (e.g., efficiency) linked to accountability evaluation, the democratic evaluation approaches share common notions about justice and pluralism. With respect to methods, the case study is an integral part of democratic evaluation, as is the critical mixed methods linked to communicative evaluation. In contrast, deliberative democratic evaluation is associated with the standard mixed methods used in many evaluations.

\section{Evaluation Practice}

The issues formulated within these respective approaches are similar as evidenced in the case vignettes. Decision makers are acknowledged within democratic and deliberative democratic evaluation. Public and stakeholders' interests are considered as critical and are addressed in all three approaches. Key concepts reflect the evaluation process. Revelation, anticipation, and building communication and partnerships constructs are substantively different, distinguishing communicative evaluation. However, there are not enough evaluation practice 
TABLE 1.

Descriptive Typology for Comparing Democratic Evaluation Genres

\begin{tabular}{|c|c|c|c|}
\hline & Democratic Evaluation & Deliberative Democratic Evaluation & Communicative Evaluation \\
\hline \multicolumn{4}{|l|}{ Evaluation Theory } \\
\hline Foundations & Liberal democracy (Locke, 1988) & $\begin{array}{l}\text { Participatory democracy } \\
\text { (Gutmann, 1987) }\end{array}$ & $\begin{array}{l}\text { Deliberative democracy } \\
\text { (Habermas, 1996) }\end{array}$ \\
\hline Values & Pluralism and informed citizenry & Democracy, justice, rationality & $\begin{array}{l}\text { Democracy, justice, } \\
\text { emancipation }\end{array}$ \\
\hline Institutional Location & $\begin{array}{l}\text { Within formal institutional } \\
\text { structures (system) }\end{array}$ & $\begin{array}{l}\text { Within formal institutional } \\
\text { structures (system) }\end{array}$ & $\begin{array}{l}\text { Within multiple public spheres } \\
\text { (lifeworld) }\end{array}$ \\
\hline Methodology & Case study & Mixed methods-synthesis & Critical mixed methods \\
\hline \multicolumn{4}{|l|}{ Evaluation Practice } \\
\hline Issues Formulation & Range of interests, pluralism & Traditional eye toward injustice & $\begin{array}{l}\text { Locally determined-Change in } \\
\text { present to 'something else' }\end{array}$ \\
\hline Key Concepts & $\begin{array}{l}\text { Confidentiality, negotiation, } \\
\text { accessibility }\end{array}$ & Dialogue, deliberation, inclusion & $\begin{array}{l}\text { Revelation, anticipation, building } \\
\text { communication and partnerships }\end{array}$ \\
\hline Evaluator Role & Information broker & $\begin{array}{l}\text { Advocate of democratic } \\
\text { principles, negotiator }\end{array}$ & $\begin{array}{l}\text { Facilitator of a particular kind of } \\
\text { conversation }\end{array}$ \\
\hline Key Justification & Right to know & $\begin{array}{l}\text { Contribute to the realization of a } \\
\text { democratic society }\end{array}$ & $\begin{array}{l}\text { Effective support for social } \\
\text { change }\end{array}$ \\
\hline Communicative Practices & Report aspiring to be 'best seller' & Traditional report & $\begin{array}{l}\text { Stimulating public discourse by } \\
\text { enabling communicative } \\
\text { networks }\end{array}$ \\
\hline
\end{tabular}


examples to judge how similar or different these processes are in communicative evaluation, relative to the other two approaches.

Each genre defines a salient role for participants or stakeholders in the evaluation. However, the articulation of these respective roles is unique, ranging from an important source of program information (democratic evaluation) to owners of the evaluation process (communicative evaluation). The evaluator role, likewise, is also individualized across these genres, with the evaluator serving as an information broker for democratic evaluation, and as an advocate of democratic principles and negotiator for deliberative democratic evaluation. In practice, these roles are likely to be comparable. On the other hand, the communicative evaluator is a facilitator of a practical deliberation aimed toward contributing to the public discourse. With respect to communicative practices, democratic and communicative evaluation are most similar. While democratic evaluation does not explicitly articulate a link to the larger context as part of its communicative practices like communicative evaluation, aspiring to prepare reports that reach best seller status certainly implies a widespread distribution of the findings beyond the original context.

\section{FUTURE DIRECTIONS}

Where do democratic evaluation approaches fit in the current educational accountability climate? None of the approaches reviewed above fit the accountability evaluation criteria delineated in NCLB, which does not include stakeholders. Democratic evaluation illuminates issues of power and authority (McKee \& Stake, 2002). In this sense, democratic evaluation will likely face challenges in these times of the audit culture characterized by power and authority. Of course, this does not mean democratic approaches should not be practiced. Democratic evaluation is intended for contexts where there are concerns about top-down control of management and education (MacDonald \& Kushner, 2004). Further, democratic evaluation fits well when institutions are interested in moving to less hierarchical, more horizontal arrangements.

The importance of democratic access and debate in addressing educational accountability issues is as critical as it has ever been. Accountability for educational outcomes is a considered to be a shared responsibility of states, school districts, public officials, educators, parents, and students (Heubert \& Hauer, 1999). At the same time, there is little discussion about who decides and how to decide what educational outcomes should be in spite of the fact these are essentially value choices. Further, there is a sense that accountability means districts and students need to be monitored closely by federal and state policy makers.

There is nothing wrong with accountability-accountability serves public interests. Hardly anyone would argue that schools should not be held accountable to ensure efficient and appropriate use of resources. Current educational accountability evaluation also serves the public interests when educational inequities are revealed by within and across school achievement comparisons. While there are issues (e.g., a lack of financial and instructional resources targeted for improving these disparities) involved in disaggregating by race and socio-economic status, these inequalities cannot be detected without such comparisons (Rizvi, 1990).

The challenge becomes how to develop educational accountability with a more democratic character. How can democratic evaluation help? Democratic evaluation approaches can play a part by staying true to their historical roots-concern with local education issues and issues of power and authority (MacDonald, 1976; Simons, 1987). In these audit culture times, local educational concerns reside between centralized authority and the teaching and learning in the classroom. Here is a space for democratic evaluation approaches (Imsen, 2003). 
Taken together, these three evaluation approaches provide a major set of resources for addressing top-down hierarchical accountability concerns in education and elsewhere. These approaches illuminate power issues and each has set of strategies for attempting to address these inequities. The democratic evaluation process attempts to shift power balances by making program knowledge a significant and valued resource, using the notion of mutual accountability. Vignette 1 reflected some of the challenges with democratic evaluation. The inclusion, dialogue, and deliberation requirements in deliberative democratic evaluation set the stage for issues to surface in the evaluation context that may otherwise remain covered or undisclosed (e.g., racial stratification in Vignette 2). Here the notion of a district self-accountability became apparent. Communicative evaluation shifts power relations by creating a horizontal, collaborative evaluation context that reflects the views of participants (Vignette 3). This provides a different lens for understanding educational or social problems. The information from the evaluation was informative about what to do and how to improve the achievement gap.

From these approaches and their respective vignettes, a democratic accountability can be imagined. How does democratic accountability fit within the audit culture? It is at the intersection of policy intention and what is actually happening. This is clearly illustrated by an article in The New York Times titled "Bait and Switch on Public Education," reporting that Congress withheld \$6 billion dollars that was intended to fund NCLB ("Bait and Switch," 2003). Essentially, NCLB requires school districts to be accountable for implementing major educational reforms such as putting qualified teachers in every classroom and ending the achievement gap between subgroups (blacks and whites). Schools that are unable to show progress in these areas will be required to pay for students to attend other schools at parents' request. In some districts, nearly $40 \%$ of schools are designated "as needing improvement." However, the funds to implement or pay for programs essential to achieving these kinds of goals are not available.

What can schools do in the face of these kinds of complexities? They can engage in democratic accountability with their communities holding themselves responsible for what they are doing. This democratic accountability is a form of self-accountability anchored by foundations and resources from democratic evaluation approaches. Mutual accountability, which particularly focuses on the gap between what the policy intended and what is actually happening, would be core principle. School personnel and the community become a self-monitoring community where this community looks at how they are implementing the school programs in general and in relationship to current policy. They jointly engage in critical reflection about school and policy implementation. These kinds of self-reflective activities can focus towards systemic issues (unequal distribution of financial and human resources in schools) so that claims about inadequate resources for proper implementation could be documented.

What is the evaluator's place in democratic accountability? Evaluators can serve public interests in at least two ways. First, evaluators can play the widely recognized external role by serving as evaluators and meta-evaluators-keeping the school and community focused on examining both strengths and how schools can be improved. An important second way evaluators can conserve public interests is by helping self-monitoring communities develop. They can help design this community. To critically engage with the community about educational concerns, knowledge about these issues must be accessible. Evaluators have the skills needed to make knowledge about education accessible and widely circulated within the public discourse. Fostering this public culture about education (Willinsky, 2003) enables practical deliberation about educational issues. 


\section{NOTES}

1. For the purposes of this paper, New Public Management refers to a set of initiatives characterized by a regulatory style that makes individuals and organizations accountable through auditable performance standards (Power, 1997). These standards are intended to improve internal performance and to make these improvements externally confirmable and public. Performance is formed by economy, efficiency, and effectiveness (Power, 1997).

2. D. Smith (1987) defines "ruling apparatus as that familiar complex of management, government, administration, professions, and intelligentsia, as well as the textually mediated discourses that coordinate it and penetrate it" (p. 107).

3. Here society is devoted to maximizing individuals' power and personal interests rather than communitarian (Habermas, 1996).

4. Saville Kushner contributed to the vignette description and case analysis.

5. Here self -accountability means schools commit to criteria of excellence that are developed with the community for providing information about the schools to the community (Rizvi, 1990).

6. Kemmis (personal communication) proposes these approaches are based on a sender-receiver communication model with a focus on which groups are "senders" and "receivers" of information.

7. Niemi and Kemmis (1999) call this seeing a program stereoscopically. Drawing on Habermas's social theory of systems and lifeworld, they propose evaluation oriented toward decision makers is linked to systems, while others like communicative evaluation are connected to lifeworld. The systems world relates to the state, institutions, its rules and regulations and how people function within their roles, charged with particular functions. Lifeworld reflects the natural world-how people relate to each other as persons with shared understandings and identities. The system and lifeworld are in a state of tension with each other.

\section{ACKNOWLEDGMENTS}

My thanks to Saville Kushner, Mel Mark, Norman Denzin and several anonymous reviewers for their suggestions.

\section{REFERENCES}

Bacon, B., Yuen, C., \& Korza, P. (1999). Animating democracy: The artistic imagination as force in civic dialogue. Washington, DC: Americans for the Arts.

Bait and switch on public education. (2003, October 21). The New York Times, p. A6.

Brooks, M., Ryan, K. E., Miron, L. (2003). Making the grade: The educational experiences of high school seniors drifting towards graduation. Preliminary evaluation report. Champaign, IL: Department of Educational Psychology, University of Illinois at Urbana.

Fetterman, D. M. (1994). Empowerment evaluation. Evaluation Practice, 15, 1-14.

Fraser, N. (1993). Rethinking the public sphere: A contribution to the critique of actually existing democracy. In B. Robbins (Ed.), The phantom public sphere (pp. 1-32). Minneapolis, MN: University of Minnesota Press.

Greene, J. C. (2000). Voices in conversation? Struggling for inclusion. In K. Ryan \& L. DeStefano (Eds.), Evaluation as a democratic process: Inclusion, dialogue, and deliberation. New directions for evaluation, No. 35: (pp. 13-26). San Francisco, CA: Jossey Bass.

Guba, E. (1969). The failure of educational evaluation. Educational Technology, 9(5), 29-38.

Guba, E., \& Lincoln, Y. (1989). Fourth generation evaluation. Newberry Park, CA: Sage.

Gutmann, A. (1987). Democratic education. Princeton, NJ: University Press.

Gutmann, A., \& Thompson, D. (1999). Democratic disagreement. In S. Macedo (Ed.), Deliberative politics: Essays on democracy and disagreement (pp. 243-279). New York: Oxford University Press. 
Habermas, J. (1989). The structural transformation of the public sphere: An inquiry into the category of the bourgeois society (T. Burger \& F. Lawrence, Trans.). Cambridge, MA: MIT Press.

Habermas, J. (1996). Three normative models of democracy. In S. Benhabib (Ed.), Democracy and difference (pp. 21-30). Princeton, NJ: Princeton University Press.

Heubert, J. P., \& Hauer, R. M. (Eds.). (1999). High stakes: Testing for tracking, promotion, and graduation. Washington, DC: National Academy Press.

House, E. (2005). Qualitative evaluation and changing social policy. In N. Denzin \& Y. Lincoln (Eds.), Handbook of qualitative research (3rd ed.). Thousand Oaks, CA: Sage Publications.

House, E., \& Howe, K. (1999). Values in evaluation and social research. Thousand Oaks, CA: Sage Publications.

Howe, K. R., \& Ashcraft, C. (in press). Deliberative democratic evaluation: Successes and limitations of an evaluation of school choice. Teachers College Record, 107(10).

Imsen, G. (2003). Democratic evaluation and evaluation for learning. In P. Haug \& T. A. Schwandt (Eds.), Evaluating educational reforms: Scandinavia perspectives (pp. 149-168). Greenwich, CT: Information Age.

Kemmis, S., \& McTaggart, R. (2000). Participatory action research: Communicative action and the public sphere. In N. Denzin \& Y. Lincoln (Eds.), Handbook of qualitative research (2nd ed., pp. 567-606). Thousand Oaks, CA: Sage.

Kemmis, S., \& McTaggart, R. (2005). Participatory action research: Communicative action and the public sphere. In N. Denzin \& Y. Lincoln (Eds.), Handbook of qualitative research (3rd ed.). Thousand Oaks, CA: Sage.

Kushner, S., Simons, H., Jones, K., \& James, D. (2003). From evidence-based practice to practicebased evidence: The idea of situated generalization. Research Papers in Education, 18, 347364.

Locke, J. (1988). Two treatises of government. New York: Cambridge University Press.

MacDonald, B. (1976). Evaluation and the control of education. In D. Tawney (Ed.), Curriculum evaluation today: Trends and implications (pp. 125-134). London: Macmillan Education.

MacDonald, B. (1999, November 11). Doctor honoris causa. Valladolid, Spain.

MacDonald, B., \& Kushner, S. (Eds.). (1982). Bread and dreams: A case study of bilingual schooling in the U.S.A. Norwich, UK: Centre for Applied Research in Education (CARE), University of East Anglia.

MacDonald, B., \& Kushner, S. (2004). Democratic evaluation. In S. Mathison (Ed.), The encyclopedia of evaluation. Thousand Oaks, CA: Sage.

MacDonald, B., \& Walker, R. (1975). Case study and the social philosophy of educational research. Cambridge Journal of Education, 5, 2-11.

MacDonald, B., \& Walker, R. (1976). Changing the curriculum. London: Open Books Publishing.

Mark, M. M., Henry, G., \& Julnes, G. (2000). Evaluation: An integrated framework for understanding, guiding, and improving policies and programs. San Francisco, CA: Jossey-Bass.

Mathsion, S. (2000). Deliberation, evaluation, democracy. In K. Ryan \& L. DeStefano (Eds.), Evaluation as a democratic process: Inclusion, dialogue and deliberation. New directions for evaluation, No. 85 (pp. 85-90). San Francisco, CA: Jossey Bass.

McKee, A., \& Stake, R. E. (2002). Making evaluation democratic in a climate of control. In L. Bresler \& A. Ardichivili (Eds.), International research in education: Experience, theory and practice (pp. 121-137). New York: Peter Lang.

Niemi, H., \& Kemmis, S. (1999). Communicative evaluation. Lifelong Learning in Europe, 4, 55-64.

No Child Left Behind Act of 2001. Pub. L. No. 107th Cong., 110 Cong. Rec. 1425. 115 Stat. (2002).

Noddings, N. (1984). Caring: A feminine approach to ethics and moral education. Berkeley, CA: University of California Press.

Power, M. (1997). The audit society. New York: Oxford Press.

Rizvi, F. (1990). Horizontal accountability. In J. Chapman (Ed.), School-based decision-making and management (pp. 299-324). Hampshire: Falmer Press. 
Ryan, K. E. (2002). Shaping educational accountability systems. American Journal of Evaluation, 23, 453-468.

Ryan, K. E., \& DeStefano, L. (2001). Dialogue as a democratizing evaluation method. Evaluation, 7, 195-210.

Ryan, K., \& Johnson, T. (2000). Democratizing evaluation: Meanings and methods from practice. In K. Ryan \& L. DeStefano (Eds.), Evaluation as a democratic process: Inclusion, dialogue and deliberation. New directions for evaluation, No. 85 (pp. 39-55). San Francisco, CA: Jossey Bass.

Simons, H. (1981). Process evaluation in the schools. In C. Lacey \& D. Lawton (Eds.), Issues in evaluation and accountability (pp. 114-146). London: Methuen.

Simons, H. (1987). Getting to know schools in a democracy: The politics and process of Evaluation. New York: Falmer.

Simons, H., Kushner, S., James, D., \& Jones, D. K. (2003). Independent external evaluation of TTA school-based consortia. Southampton: University of Southampton and University of the West of England 1999-2001.

Smith, D. (1987). The everyday world as problematic: A feminist sociology. Boston, MA: Northeastern University Press.

Stake, R. E. (1984). Program evaluation, particularly responsive evaluation. In G. F. Madaus, M. Scriven, \& D. L. Stufflebeam (Eds.), Evaluation models (pp. 287-310). Boston: Kluwer-Nijhoff.

Stake, R. E. (1995). The art of case study research. Thousand Oaks, CA: Sage.

Stake, R. E. (2001). How modern democracies are shaping evaluation and the emerging challenges for evaluation. American Journal of Evaluation, 22, 349-354.

Whitmore, E. (Ed.). (1998). Understanding and practicing participatory evaluation. New directions for evaluation, No. 80. San Francisco, CA: Jossey-Bass.

Willinsky, J. (2003, April). The democratic responsibilities of scientific inquiry in education. Paper presented at the Annual Meeting of American Educational Research Association, Chicago, IL.

Young, I. M. (1999). Justice, inclusion, and deliberative democracy. In S. Macedo (Ed.), Deliberative politics: Essays on democracy and disagreement (pp. 151-158). New York: Oxford University Press. 